\title{
Understanding Gender, Race and Ethnicity in Colorectal Cancer Screening
}

Heather B. Fagan ${ }^{1 *}$, Richard C. Wender ${ }^{3}$, Randa Sifri ${ }^{2}$, Kristen Isaac ${ }^{1}$ and Melaine Eisele ${ }^{2}$

${ }^{1}$ Department of Family \& Community Medicine, Christiana Care Health System, USA

${ }^{2}$ Department of Family and Community Medicine, Thomas Jefferson University Hospitals, Philadelphia, USA

${ }^{3}$ American Cancer Society, USA

\begin{abstract}
Background: Colorectal cancer (CRC) is the third most common cancer and the third leading cause of cancer death in both men and women in the United States. The overall rate of CRC screening remains unacceptably low. To increase $\mathrm{CRC}$ screening rates, populations who are refractory to screening must be identified. Identifying barriers and facilitators of screening specific to these groups will assist the development of targeted interventions to improve CRC screening.

Methods: This review synthesizes the published literature regarding the role of gender, race and ethnicity in receiving colorectal cancer screening in the United States. Specifically, this review examines cross-sectional and prospective studies of colorectal cancer screening. These studies provide important data about the impact of race, gender and ethnicity on colorectal cancer screening rates.

Results: Female gender and non-white race are not consistent barriers to screening. However, Hispanic ethnicity does seem to consistently confer a barrier to screening.

Conclusion: The impact of female gender and non-white race on screening is inconsistent suggesting that other factors (e.g. socioeconomic status, access to care) play a greater role and perhaps that targeted efforts have been effective in addressing disparity. Improved CRC screening rates in these groups can inform approaches to improving rates in other groups, such as Hispanics, who consistently fall behind.
\end{abstract}

Keywords: Colorectal cancer screening; Race disparity; Gender disparity; Prevention

\section{Introduction}

Colorectal cancer (CRC) is the third most common cancer and the third leading cause of cancer death in both men and women in the United States. Since CRC impacts both genders, it is actually the second most common cause of cancer death overall [1]. CRC screening has been proven to result in a reduction in CRC mortality [2]. CRC screening reduces mortality both through the earlier detection of cancers and offers the opportunity for primary prevention i.e. removal of pre-cancerous polyps [3]. The American Cancer Society (ACS) and the United States Preventive Services Task Force (USPSTF) recommend screening for individuals over the age of 50, regardless of race, gender or ethnicity. Due in large part to the increasing awareness and availability of colonoscopy, the rates of CRC screening have risen significantly in the last 10 years. However, the overall rate of CRC screening remains unacceptably low, around $60 \%[4]$.

To increase CRC screening rates, populations who are refractory to screening must be identified and assisted. Numerous factors influence whether or not a patient participates in screening. This review focuses on three key determinants of screening: gender, race, and ethnicity.

\section{Methods}

The authors classify race and ethnicity per US Federal recommendations [5]. The literature search for this review was conducted by a certified medical librarian and based on the strategy used by Vernon [6] in a comprehensive 1997 review of participation in CRC screening. The literature review is current as of October 2014. We began with the MeSH terms, colorectal neoplasms/ di, pc [Diagnosis, Prevention and Control] and mass screening to identify $>$ 130,000 articles. MeSH headings were added to capture gender, race and ethnicity and restricted our review to studies in English and in the United States. Any study that examined an outcome of stool blood testing, endoscopy or a combination of both was included in analysis. Studies with either 1) gender or 2) race or 3) ethnicity as a predictor of screening in either multivariate or univariate analysis were included $(\mathrm{n}=121)$. Authors reviewed the 121 potential articles individually for quality and applicability $(\mathrm{n}=45)$. Occasionally studies would report more than one outcome (e.g. fecal occult blood test (FOBT) and colonoscopy as two separate outcomes). When there was a differential association for our variable of interest (e.g. gender) and the outcome (e.g. a positive association between female gender and FOBT but no significant association between female gender and colonoscopy) we reported the analyses separately i.e. as two entries in our chart. So, some studies appear more than once in the tables [7-11].

\section{Results}

\section{Extensive literature review}

Gender in CRC screening: CRC screening rates in U.S. men and women are equivalent [4]. Table 1 presents the literature on gender and CRC screening. We identified 36 analyses which included gender. Fifteen articles found no screening differences for women vs. men while 14 showed lower screening and seven showed a positive association between female gender and CRC screening. There is no significant

*Corresponding author: Heather B. Fagan, Department of Family \& Community Medicine, Christiana Care Health System, 1400 N Washington St, Room 328, Wilmington DE 19801, USA, Tel: 302-320-1335; Fax: 302-320-1355; E-mail: Hbittner-fagan@christianacare.org

Received August 13, 2014; Accepted March 18, 2015; Published March 25, 2015

Citation: Heather B. Fagan, Richard C. Wender, Randa Sifri', Kristen Isaac, Melaine Eisele (2015) Understanding Gender, Race and Ethnicity in Colorectal Cancer Screening. Health Care Current Reviews 3: 131. doi: 10.4172/2375-4273.1000131

Copyright: ( 2015 Fagan HB, et al. This is an open-access article distributed under the terms of the Creative Commons Attribution License, which permits unrestricted use, distribution, and reproduction in any medium, provided the original author and source are credited. 
Citation: Heather B. Fagan, Richard C. Wender, Randa Sifri', Kristen Isaac, Melaine Eisele (2015) Understanding Gender, Race and Ethnicity in Colorectal Cancer Screening. Health Care Current Reviews 3: 131. doi: 10.4172/2375-4273.1000131

Page 2 of 6

\begin{tabular}{|c|c|c|}
\hline Studies w/Negative Association & Sample & Outcome \\
\hline Harmon et al. [25] & Washington State (Insured) $(\mathrm{N}=140,398)$ & Overall CRC Screening \\
\hline Wernli et al. [26] & Multiethnic cohort (MEC) $(\mathrm{N}=81,223)$ & Colonoscopy \\
\hline Fenton et al.[27] & Washington State Health Plan $(\mathrm{N}=11,110)$ & FOBT \\
\hline de Bosset et al. [15] & Virginia BRFSS ${ }^{1}$ insured $(\mathrm{N}=2,887)$ & Overall CRC Screening \\
\hline Peterson et al. [10] & $\mathrm{NHIS}^{2}(\mathrm{~N}=32,374)$ & Endoscopy \\
\hline Meissner et al. [21] & $\mathrm{NHIS}^{2}(\mathrm{~N}=4,692)$ & Sigmoidoscopy/ Any Test \\
\hline Zhao et al.[11] & Physician Claims $\mathrm{CMS}^{3}(\mathrm{~N}=691,018)$ & BE/Sigmoidoscopy/Any Test \\
\hline Christman [28] & Medical Records from $\mathrm{CHC}^{4}(\mathrm{~N}=1,196)$ & Overall CRC Screening \\
\hline Etizioni [29] & California HIS ${ }^{5}(\mathrm{~N}=22,343)$ & Overall CRC Screening \\
\hline Rao et al.[12] & $\mathrm{NHIS}^{2}(\mathrm{~N}=38,209)$ & Overall CRC Screening \\
\hline Brawarsky et al.[30] & Massachusetts BRFSS ${ }^{1}(\mathrm{~N}=869)$ & Overall CRC screening \\
\hline Bell et al.[7] & North Carolina BRFSS ${ }^{1}(\mathrm{~N}=5700)$ & FOBT \\
\hline Coughlin et al.[31] & BRFSS $^{1}(\mathrm{~N}=61,412)$ & Colonoscopy/Sigmoidoscopy \\
\hline McMahon et al.[9] & Michigan Medicare & Colonoscopy \\
\hline Studies w/no Significant Association & Sample & Outcome \\
\hline Fenton et al.[27] & Washington State Health Plan $(\mathrm{N}=11,110)$ & Any non-FOBT test \\
\hline Hood et al.[17] & All African Americans $(\mathrm{N}=439)$ & Overall CRC Screening \\
\hline Bazargan et al.[32] & Urban African American \& Hispanics $(\mathrm{N}=306)$ & Overall CRC Screening \\
\hline Griffith et al.[16] & Maryland $(\mathrm{N}=5,040)$ & Overall CRC Screening \\
\hline Schenck et al.[33] & Medicare $(\mathrm{N}=82,996,703)$ & Overall CRC Screening \\
\hline CDC et al.[48] & BRFSS $^{1}(\mathrm{~N}=201,157)$ & SBT and/or Colonoscopy \\
\hline Trivers et al.[34] & $\mathrm{NHIS}^{2}(\mathrm{~N}=6,463(2000) \& 7,364(2005)$ & Overall CRC Screening \\
\hline Lawsin et al.[35] & Urban African Americans $(\mathrm{N}=111)$ & FOBT \\
\hline Peterson et al.[10] & $\mathrm{NHIS}^{2}(\mathrm{~N}=32,374)$ & Overall CRC Screening \\
\hline Ata et al.[20] & $\mathrm{NHIS}^{2}(\mathrm{~N}=358)$ & Overall CRC Screening \\
\hline Callcut et al.[36] & Statewide Claims $(N=103,580)$ & Endoscopy \\
\hline Meissner et al.[21] & $\mathrm{NHIS}^{2}(\mathrm{~N}=4,692)$ & Colonoscopy or FOBT \\
\hline Zimmerman et al.[37] & Inner City Health Clinic $(\mathrm{N}=325)$ & Colonoscopy \\
\hline Fisher et al.[38] & North Carolina Colon Cancer Study $(\mathrm{N}=1,051)$ & Overall CRC Screening \\
\hline Taylor et al.[39] & Urban African Americans $(\mathrm{N}=74)$ & $\begin{array}{l}\text { Sigmoidoscopy, Colonoscopy \& FOBT with } \\
\text { greater than M trend }\end{array}$ \\
\hline Studies w/Positive Association & Sample & Outcome \\
\hline Martinez et al.[22] & African American Medicare beneficiaries in Baltimore $(\mathrm{N}=1,552)$ & Overall CRC screening \\
\hline Hood et al.[17] & All African Americans $(\mathrm{N}=439)$ & Colonoscopy \\
\hline Peterson et al.[10] & $\mathrm{NHIS}^{2}(\mathrm{~N}=32,374)$ & FOBT \\
\hline Zhao et al.[11] & Tennessee $\mathrm{CMS}^{3}$ claims $(\mathrm{N}=691,018)$ & FOBT \\
\hline Bell et al 2001[7] & North Carolina BRFSS ${ }^{1}(\mathrm{~N}=5,700)$ & FOBT \\
\hline Coughlin et al.[31] & BRFSS $^{1}(\mathrm{~N}=61,412)$ & FOBT \\
\hline McMahon et al.[9] & Michigan Medicare & BE/Sigmoidoscopy \\
\hline
\end{tabular}

${ }^{1}$ Behavioral Risk Factor Surveillance Survey

${ }^{2}$ National Health Interview Survey (NHIS)

${ }^{3}$ Centers for Medicare and Medicaid Services (CMS)

${ }^{4}$ Community Health Centers $(\mathrm{CHC})$

${ }^{5}$ Health Interview Survey (HIS)

Table 1: CRC screening in Women.

change in the pattern when eliminating studies which do not include colonoscopy, the most common choice of CRC testing. Nine studies showed no association with female gender, seven studies showed a negative association and one, show a positive association.

Race in CRC Screening: Disparities in CRC mortality persist in racial subgroups and only around $49 \%$ of eligible African-Americans undergo CRC screening [4]. We identified 38 analyses which examined race and CRC screening. Table 2 presents CRC screening outcomes for individuals of non-white race. Non-white (African American/Black) race was associated with lower rates of screening in 18 studies. There was no association between race and screening in 15 studies. In 5 studies, a positive association was noted. Most analyses used colonoscopy or overall CRC as their outcome of interest. The majority of these analyses were adjusted for some measure of socio economic status (SES) or access to care. When considering only studies which utilized national data sets and included colonoscopy a clearer pattern emerges, 12 studies revealed a negative association between African American/Black race and CRC screening while five showed no association, and one showed a positive association.

Ethnicity in CRC Screening: Only around 37\% of eligible Hispanics undergo CRC screening [4]. Table 3 presents data on ethnicity and CRC screening. Twenty-five studies examined ethnicity (Hispanic vs non-Hispanic) as a predictor of CRC screening. Twenty studies demonstrated a negative association between 
Citation: Heather B. Fagan, Richard C. Wender, Randa Sifri', Kristen Isaac, Melaine Eisele (2015) Understanding Gender, Race and Ethnicity in Colorectal Cancer Screening. Health Care Current Reviews 3: 131. doi: 10.4172/2375-4273.1000131

Page 3 of 6

\begin{tabular}{|c|c|c|}
\hline Studies w/Negative Association & Sample & Outcome \\
\hline Harmon et al.[25] & Multiethnic cohort (MEC) $(\mathrm{N}=140,398)$ & Colonoscopy \\
\hline Liss et al.[40] & BRFSS $^{1}(\mathrm{~N}=226,546)$ & Overall CRC Screening \\
\hline May et al.[41] & Los Angeles Veterans Affairs System & Overall CRC Screening \\
\hline CDC et al.[48] & BRFSS $^{1}(\mathrm{~N}=201,157)$ & Colonoscopy \\
\hline Brounts et al.[42] & Insurance Claims (Tricare) $(\mathrm{N}=17,252)$ & Overall CRC Screening and Colonoscopy \\
\hline Meissner et al.[43] & $\mathrm{NHIS}^{2}$ (Males) $(\mathrm{N}=3,394)$ & Overall CRC Screening \\
\hline CDC et al.[48] & BRFSS $^{1}$ & FOBT and/or Colonoscopy \\
\hline Cronan et al.[44] & Low Income Random/Public Sample (N=158) & Colonoscopy \\
\hline Shih et al.[45] & $\mathrm{NHIS}^{2}(\mathrm{~N}=38,633)$ & Overall CRC Screening \\
\hline Peterson et al.[10] & $\mathrm{NHIS}^{2}$ (Black Women) $(\mathrm{N}=32,374)$ & Overall CRC Screening \\
\hline Zhao et al.[11] & Tennessee $\mathrm{CMS}^{3}$ Claims $(\mathrm{N}=691,018)$ & Any 1 of 3 test \\
\hline Zimmerman et al.[37] & Inner City Health Clinic N=325) & Colonoscopy \\
\hline Christman et al.[28] & $\mathrm{CHC}^{4}(\mathrm{~N}=1,196)$ & Overall CRC Screening \\
\hline Bell et al.[7] & North Carolina BRFSS ${ }^{1}(\mathrm{~N}=5,700)$ & FOBT \\
\hline Hsia et al.[46] & Women's Health Initiative $(\mathrm{N}=55,278)$ & FOBT or Sigmoidoscopy \\
\hline McMahon et al.[9] & Michigan Medicare & BE/Sigmoidoscopy \\
\hline Studies w/no Significant Association & Sample & Outcome \\
\hline Modiri et al.[47] & California $\mathrm{HIS}^{5}(\mathrm{~N}=10,596,208)$ & Overall CRC Screening \\
\hline Cole et al.[48] & BRFSS $^{1}(\mathrm{~N}=1,036,001,646)$ & Overall CRC Screening \\
\hline CDC et al.[8] & BRFSS $^{1}(\mathrm{~N}=201,157)$ & Colonoscopy \\
\hline Bazargan et al.[32] & Urban African American \& Hispanics $(\mathrm{N}=306)$ & Overall CRC Screening \\
\hline Doubeni et al.[49] & Medicare Enrollees $(\mathrm{N}=23,923)$ & Endoscopy/ Overall CRC Screening \\
\hline Meissner et al.[43] & $\mathrm{NHIS}^{2}$ Females $(\mathrm{N}=4,533)$ & Overall CRC Screening \\
\hline Katz et al.[50] & Low Income Women (CARES Project) $(\mathrm{N}=2,098)$ & Overall CRC Screening \\
\hline Peterson et al.[10] & $\mathrm{NHIS}^{2}$ (Black Men) $(\mathrm{N}=32,374)$ & Overall CRC Screening \\
\hline Ata et al.[20] & $\mathrm{NHIS}^{2}(\mathrm{~N}=358)$ & Overall CRC Screening \\
\hline Brawarsky et al.[30] & Massachusetts BRFSS ${ }^{1}(\mathrm{~N}=869)$ & Overall CRC Screening \\
\hline Goel et al.[51] & $\mathrm{NHIS}^{2}(\mathrm{~N}=32,440)$ & Sigmoidoscopy \\
\hline Coughlin et al.[52] & BRFSS $^{1}(\mathrm{~N}=106,572)$ & Sigmoidoscopy or Colonoscopy \\
\hline Bell et al.[7] & North Carolina BRFSS ${ }^{1}(\mathrm{~N}=5,700)$ & Sig/Procto, FOBT \& Sig/P, either test \\
\hline Studies w/Positive Association & Sample & Outcome \\
\hline Oluyemi et al.[53] & BRFSS $^{1}$ & Overall CRC Screening \\
\hline CDC et al.[8] & BRFSS $^{1}(N=201,157)$ & FOBT \\
\hline Zhao et al.[11] & Tennessee $\mathrm{CMS}^{3}$ Claims $(\mathrm{N}=691,018)$ & $\mathrm{BE}$ \\
\hline Dolan et al.[54] & Veterans Affairs $(\mathrm{N}=1,688)$ & Overall CRC Screening \\
\hline O'Malley et al.[55] & Low Income Urban $(\mathrm{N}=1,205)$ & FOBT \\
\hline McMahon et al.[9] & Michigan Medical Claims & Colonoscopy \\
\hline
\end{tabular}

${ }^{1}$ Behavioral Risk Factor Surveillance Survey (BRFSS)

${ }^{2}$ National Health Interview Survey (NHIS)

${ }^{3}$ Centers for Medicare and Medicaid Services (CMS)

${ }^{4}$ Community Health Centers $(\mathrm{CHC})$

${ }^{5}$ Health Interview Survey (HIS)

Table 2: CRC screening and Non-white Race.

Hispanic ethnicity and CRC screening. Four studies demonstrated no significant association with CRC screening and one showed a positive association with CRC screening and Hispanic ethnicity. The study with a positive association was conducted in men only, all of whom were insured. There is a predominant pattern whereas Hispanic ethnicity is negatively associated with CRC screening. The majority of these studies were adjusted for some measure of SES or access to care and utilized large data sets e.g. state Behavioral Risk Factor Surveillance Study (BRFSS) or National Health Interview Survey Data (NHIS).

\section{Discussion}

Improvements in CRC screening have not equally permeated our society and mortality disparities persist. Socioeconomic status, culture and lack of adequate health insurance have been critical barriers [13]. Variation in disparity by three factors, race, gender and ethnicity presents a complex picture. SES and access to care are variables that likely cluster differently depending on race, gender, and ethnic subgroup. SES and access are meaningful determinants of screening and these modifiable factors represent an opportunity for improvement. 
Citation: Heather B. Fagan, Richard C. Wender, Randa Sifri', Kristen Isaac, Melaine Eisele (2015) Understanding Gender, Race and Ethnicity in Colorectal Cancer Screening. Health Care Current Reviews 3: 131. doi: 10.4172/2375-4273.1000131

Page 4 of 6

\begin{tabular}{|c|c|c|}
\hline Studies w/Negative Association & Sample & Outcome \\
\hline Liss et al.[40] & BRFSS $^{1}(\mathrm{~N}=226,546)$ & Overall CRC Screening \\
\hline Modiri et al.[47] & California $\mathrm{HIS}^{2}(\mathrm{~N}=10,596,208)$ & Overall CRC Screening \\
\hline Cole et al.[48] & BRFSS $(N=1,036,001,646)$ & Overall CRC Screening \\
\hline Brounts et al.[42] & Tricare Insurance $(\mathrm{N}=17,252)$ & Overall CRC Screening and Colonoscopy \\
\hline Meissner et al.[43] & $\mathrm{NHIS}^{3}$ (Men and Women) $(\mathrm{N}=7,927)$ & Overall CRC Screening \\
\hline Schenck et al.[33] & Medicare $(\mathrm{N}=82,996,703)$ & Overall CRC Screening \\
\hline CDC et al.[8] & BRFSS $^{1}$ & FOBT and/or Colonoscopy \\
\hline Cronan et al.[44] & Low Income Random/Public Sample $(\mathrm{N}=158)$ & FOBT, Colonoscopy or Sigmoidoscopy \\
\hline Shih et al.[45] & $\mathrm{NHIS}^{3}(\mathrm{~N}=38,633)$ & Overall CRC Screening \\
\hline Trivers et al.[34] & $\mathrm{NHIS}^{3}$ (women) $(\mathrm{N}=13,827)$ & Overall CRC Screening \\
\hline Peterson et al.[10] & $\mathrm{NHIS}^{3}(\mathrm{~N}=32,374)$ & Overall CRC Screening \\
\hline Ata et al.[20] & $\mathrm{NHIS}^{3}(\mathrm{~N}=358)$ & Overall CRC Screening \\
\hline Callcut et al.[36] & Over 60 yrs $(N=103,580)$ & Colonoscopy \\
\hline Shah et al.[56] & $\mathrm{NHIS}^{3}(\mathrm{~N}=38,633)$ & Overall CRC Screening \\
\hline Etzioni et al.[29] & California $\mathrm{HIS}^{2}(\mathrm{~N}=22,343)$ & Overall CRC Screening \\
\hline Rao et al.[12] & $\mathrm{NHIS}^{3}(\mathrm{~N}=38,209)$ & Overall CRC Screening \\
\hline Goel et al.[51] & $\mathrm{NHIS}^{3}(\mathrm{~N}=32,440)$ & FOBT/Sigmoidoscopy \\
\hline Coughlin et al.[52] & $\begin{array}{c}\text { BRFSS }^{1} \\
\text { (Urban, Metro, Rural) }(\mathrm{N}=106,572)\end{array}$ & Colonoscopy or Sigmoidoscopy \\
\hline Hsia et al.[46] & Women's Health Initiative $(\mathrm{N}=55,278)$ & FOBT or Sigmoidoscopy \\
\hline Coughlin et al.[31] & BRFSS $^{1}(\mathrm{~N}=61,412)$ & FOBT/Overall CRC screening \\
\hline Studies w/no Significant Association & Sample & Outcome \\
\hline Bazargan et al.[32] & Urban African Americans \& Hispanics $(\mathrm{N}=306)$ & Overall CRC Screening \\
\hline Doubeni et al.[49] & Medicare $(\mathrm{N}=23,923)$ & Endoscopy/Overall CRC Screening \\
\hline Christman et al.[28] & Medical Records from $\mathrm{CHC}^{4}(\mathrm{~N}=1,196)$ & Overall CRC Screening \\
\hline Etzioni et al.[29] & California $\mathrm{HIS}^{2}(\mathrm{~N}=22,343)$ & Overall CRC Screening \\
\hline Studies w/Positive Association & Sample & Outcome \\
\hline Coughlin et al.[31] & Suburban BRFSS ${ }^{1}(\mathrm{~N}=106,572)$ & Colonoscopy or Sigmoidoscopy \\
\hline
\end{tabular}

1 Behavioral Risk Factor Surveillance Survey (BRFSS)

2 Health Interview Survey (HIS)

3 National Health Interview Survey (NHIS)

4 Community Health Centers $(\mathrm{CHC})$

Table 3: CRC screening and Hispanic Ethnicity.

The "gender gap" is closing. This reduction in the gender gap is credited in part to rapid uptake of colonoscopy by women and public health efforts to dispel the myth that CRC is a "man's disease". Improved CRC screening in women will be a success story to guide improved screening in other groups. Interestingly, African American males are less likely to screen when compared with their female counterparts [17]. Given that women access the health care system more frequently than men [14], women may more ready and able to respond to screening messages and recommendations. Of the four studies which specifically examined insurance as a predictor of CRC screening [8,15-17], one stratified according to gender. The effect of not having insurance was strongly predictive of CRC screening in men but not in women [14]. For men, lack of insurance may equate to full disengagement from the care system while African American women may be more able to work around this barrier and remain connected to the health care system.

The national racial gap in CRC screening rates is not yet closed [18]. A small majority of the studies included here, examining race and CRC screening, indicated that Black or African-American race was associated with lower rates of screening. When considering only those studies in the last 10 years with a national cohort; a more distinct pattern of negative association emerges; there are 11 studies showing a negative association between race and CRC screening and six showing no association. Some of the differences may be regional and may include state-based variations in funding or outreach programs. In Delaware, which has one of the highest statewide CRC screening rate, community-based outreach targeted specifically to African Americans is credited with eliminating race-based discrepancies in CRC screening [19]. Likewise, one of the studies which showed no negative association with race was done in Massachusetts which has universal access and very high rates of screening compared with other states. Other factors which may explain this variability include difference between black men and black women, differences in urban vs. rural and again, SES and access $[10,20,21]$.

The variations in this literature demonstrate that gender and race are not consistently barriers to screening. However, Hispanic ethnicity does seem to consistently confer a barrier to screening. While individual preferences and cultural/social biases undoubtedly contribute to racial, gender and ethnic disparities, cancer burden in underserved groups also relates to socioeconomic status $[1,12]$. In fact, lower socioeconomic status confers increased cancer risk regardless of race. However, the impact of SES on screening is variable within race/gender subgroups.

This literature on Hispanic ethnicity and CRC screening was the most straightforward. A clear majority of studies demonstrate that Hispanic ethnicity is associated with a lower likelihood of having been screened. This is not surprising given that this group has consistently been found to have the lowest cancer screening rate nationally. Literature in this area suggests that certain subgroups, e.g. Mexican women and newer immigrants and non-English speakers, may be especially at risk [22]. Social integration or connectedness may also be very important in cancer screening in Hispanics [23]. The path to help Hispanics to 
Citation: Heather B. Fagan, Richard C. Wender, Randa Sifri', Kristen Isaac, Melaine Eisele (2015) Understanding Gender, Race and Ethnicity in Colorectal Cancer Screening. Health Care Current Reviews 3: 131. doi: 10.4172/2375-4273.1000131

Page 5 of 6

complete CRC screening is not well elucidated but finding this path will become increasingly crucial as this minority grows to represent an increasing proportion of the U.S. population.

\section{Conclusion}

Although CRC screening rates are improving, disparities in screening and mortality persist. How barriers and facilitators interact to promote or reduce screening disparities is complex and not yet fully elucidated. Future research should seek to characterize barriers and facilitators, particularly in Hispanics, under/uninsured and individuals of low SES. In populations experiencing low rates of screening, more interventional studies are needed.

\section{Acknowledgements}

Barbara Henry MLS, was essential to this effort and the authors thank her for her patience and diligence. This work was supported by an Institutional Development Award (IDeA) from the National Institute of General Medical Sciences of the National Institutes of Health under grant number U54-GM104941 (PI: Binder-Macleod). We would like to acknowledge Deena Chisholm from the Department of Family and Community Medicine/Christiana Care Health System for her contributions to the paper.

\section{References}

1. American Cancer Society (2012) Cancer Facts \& Figures 2012. American Cancer Society, Atlanta.

2. Mandel JS, Bond JH, Church TR (1993) Reducing mortality from colorecta cancer by screening for fecal occult blood. Minnesota Colon Cancer Control Study. N Engl J Med 328: 1365-1371.

3. Zauber AG, Winawer SJ, O'Brien MJ, Lansdorp-Vogelaar L, Ballegooijen MN, et al. (2012) Colonoscopic polypectomy and long-term prevention of colorectalcancer deaths. N Engl J Med 366: 687-696.

4. American Cancer Society (2014) Colorectal Cancer Facts \& Figures 20142016. Atlanta: American Cancer Society.

5. The White House Office of Management and Budget (1995) Standards for the Classification of Federal Data on Race and Ethnicity.

6. Vernon SW (1997) Participation in colorectal cancer screening: a review. J Nat Cancer Inst 89:1406-1422.

7. Bell RA, Shelton BJ, Paskett, ED (2001) Colorectal cancer screening in North Carolina: associations with diabetes mellitus and demographic and health characteristics. Prev Med 32: 163-167.

8. Centers for Disease Control (CDC) (2010) Vital signs: colorectal cance screening among adults aged 50-75 years - United States, 2008. MMWR Morb Mortal Wkly Rep 59: 808-812.

9. McMahon LF Jr, Wolfe RA, Huang S, Tedeschi, P, Manning W Jr, et al. (1999) Racial and gender variation in use of diagnostic colonic procedures in the Michigan Medicare population. Med Care 37: 712-717.

10. Peterson NB, Murff HJ, Ness RM, Dittus RS (2007) Colorectal cancer screening among men and women in the United States. J Womens Health (Larchmt) 16 : 57-65.

11. Zhao BB, Kilbourne B, Stain SC, Van Cain A, Briggs NC, et al. (2006) Racia disparities and trends in use of colorectal procedures among Tennessee elderly (1996-2000). Ethn Dis Spring 16: 412-420.

12. Rao RS, Graubard BI, Breen N, Gastwirth JL (2004) Understanding the factors underlying disparities in cancer screening rates using the Peters-Belson approach: results from the 1998 National Health Interview Survey. Med Care 42: $789-800$

13. Ward E, Halpern M, Schrag N (2008) Association of Insurance with Cancer Care Utilization and Outcomes. CA Cancer J Clin 58: 9-31.

14. Bertakis KD (2009) The influence of gender on the doctor-patient interaction. Patient Educ Couns 76: 356-360

15. de Bosset V, Atashili J, Miller W, Pignone M (2008) Health insurance-related disparities in colorectal cancer screening in Virginia. Cancer Epidemio Biomarkers Prev 17: 834-837.

16. Griffith KA (2009) Biological, psychological and behavioral, and social variables influencing colorectal cancer screening in African Americans. Nurs Res 58 : 312-320.

17. Hood S, Thompson VL, Cogbill S, Arnold LD, Talley M, et al. (2010) African American's self-report patterns using the National Cancer Institute Colorecta Cancer Screening questionnaire. J Cancer Educ 25: 431-436.

18. Centers for Disease Control and Prevention (CDC) (2008) Use of colorectal cancer tests--United States, 2002, 2004, and 2006. MMWR Morb Mortal Wkly Rep 57: 253-258.

19. Delaware Cancer Consortium Web Site.

20. 20. Ata A, Elzey JD, Insaf TZ, Grau AM, Stain SC et al. (2006) Colorectal cance prevention: adherence patterns and correlates of tests done for screening purposes within United States populations. Cancer Detect Prev 30: 134-143.

21. Meissner HI, Breen N, Klabunde CN, Vernon SW (2006) Patterns of colorectal cancer screening uptake among men and women in the United States. Cancer Epidemiol Biomarkers Prev 15: 389-394.

22. Martinez KA, Pollack CE, Phelan DF, Markakis D, Bone L, et al. (2013) Gender differences in Correlates of Colorectal Cancer Screening Among Black Medicare Beneficiaries in Baltimore. Cancer Epidemiol Biomarkers Prev 22 1037-1042.

23. Zambrana RE, Breen N, Fox SA, Gutierrez-Mohamed ML (1999) Use of cancer screening practices by Hispanic women: analyses by subgroup. Prev Med 29 466-477.

24. Suarez L, Ramirez AG, Villarreal R (2000) Social networks and cancer screening in four U.S. Hispanic groups. Am J Prev Med 19: 47-52.

25. 25. Harmon BE, Little MA, Woekel ED, Ettienne R, Long CR, et al. (2014) Ethnic differences and predictors of colonoscopy, prostate-specific antigen, and mammography screening participation in the multiethnic cohort. Cance Epidemiol 38: 162-167.

26. Wernli KJ (2014). Patterns of Colorectal Cancer Screening Uptake in Newly Eligible Men and Women. Cancer Epidemiol Biomarkers Prev 23: 1230-1237.

27. Fenton JJ, Elmore JG, Buist DS, Reid RJ, Tancredi, DJ, et al. (2010) Longitudinal adherence with fecal occult blood test screening in community practice. Ann Fam Med 8: 397-401.

28. Christman LK, Abdulla R, Jacobsen PB (2004) Colorectal cancer screening among a sample of community health center attendees. J Health Care Poor Underserved 15: 281-293.

29. Etzioni DA, Ponce NA, Babey SH (2004) A population-based study of colorectal cancer test use: results from the 2001 California Health Interview Survey. Cancer 101: 2523-2532.

30. Brawarsky P, Brooks DR, Mucci LA (2003) Correlates of colorectal cancer testing in Massachusetts men and women. Prev Med 36: 659-668.

31. 31.Coughlin SS, Thompson TD (1999) Colorectal cancer screening practices among men and women in rural and nonrural areas of the United States, 1999. J Rural Health Spring 20:118-124.

32. Bazargan M, Ani C, Bazargan-Hejazi S, Baker RS, Bastani R, et al. (2009) Colorectal cancer screening among underserved minority population: discrepancy between physicians' recommended, scheduled, and completed tests. Patient Educ Couns 76: 240-247.

33. Schenck AP, Peacock SC, Klabunde CN, Lapin P, Coan JF, et al. (2009) Trends in colorectal cancer test use in the medicare population, 1998-2005. Am J Prev Med 37: 1-7.

34. Trivers KF, Shaw KM, Sabatino SA, Shapiro JA, Coates, RJ, et al. (2008) Trends in colorectal cancer screening disparities in people aged 50-64 years, 2000-2005. Am J Prev Med 35: 185-193.

35. Lawsin C, DuHamel K, Weiss A, Rakowski W, Jandorf L, et al. (2007) Colorectal cancer screening among low-income African Americans in East Harlem: a theoretical approach to understanding barriers and promoters to screening. $J$ Urban Health 84: 32-44.

36. Callcut RA, Kaufman S, Stone-Newsom R, Remington P, Mahvi D, et al. (2006) Gender disparities in colorectal cancer screening: true or false? J Gastrointest Surg 10: 1409-1417.

37. Zimmerman RK, Tabbarah M, Trauth J, Nowalk MP, Ricci EM, et al. (2006) Predictors of lower endoscopy use among patients at three inner-city neighborhood health centers. J Urban Health 83: 221-230. 
Citation: Heather B. Fagan, Richard C. Wender, Randa Sifri', Kristen Isaac, Melaine Eisele (2015) Understanding Gender, Race and Ethnicity in Colorectal Cancer Screening. Health Care Current Reviews 3: 131. doi: 10.4172/2375-4273.1000131

Page 6 of 6

38. Fisher DA, Dougherty K, Martin C, Galanko J, Provenzale D, et al. (2004) Race and colorectal cancer screening: a population-based study in North Carolina. N C Med J 65: 12-15.

39. Taylor V, Lessler D, Mertens K (2003) Colorectal cancer screening among African Americans: the importance of physician recommendation. J Natl Med Assoc 95: 806-812

40. Liss DT, Baker DW (2014) Understanding Current Racial/Ethnic Disparities in Colorectal Cancer Screening in the United States; The Contribution of Socioeconomic Status Access to Care. Am J Prev Med 46: 228-236.

41. May FP (2014) Low uptake of colorectal cancer screening among African American in an integrated Veterans Affairs health care network. Gastrointest Endosc 80: 291-298.

42. Brounts LR, Lehmann RK, Lesperance KE, Brown TA, Steele SR ,et al. (2009) Improved rates of colorectal cancer screening in an equal access population. Am J Surg 197: 609-612.

43. Meissner HI, Yabroff KR, Dodd KW, Leader AE, Ballard-Barbash R, et al. (2009) Are patterns of health behavior associated with cancer screening? Am J Health Promot 23: 168-175.

44. Cronan TA, Devos-Comby L, Villalta I, Gallagher R (2008) Ethnic differences in colorectal cancer screening. J Psychosoc Oncol 26: 63-86.

45. Shih YC, Elting LS, Levin B (2008) Disparities in colorectal screening between US-born and foreign-born populations: evidence from the 2000 National Health Interview Survey. J Cancer Educ 23:18-25.

46. Hsia J, Kemper E, Kiefe C (2000) The importance of health insurance as a determinant of cancer screening: evidence from the Women's Health Initiative. Prev Med 31: 261-270.

47. Modiri A, Makipour K, Gomes J, Friedenberg F (2013) Predictors of colorectal cancer testing using the California Health Inventory Survey. World J Gastroenterol 19: 1247-1255.

48. Cole AM, Jackson JE, Doescher M (2012) Colorectal Cancer Screening Disparities for Rural Minorities in the United States. Journal of Primary Care and Community Health 4: 106-111.

49. Doubeni CA, Laiyemo AO, Reed G, Field TS, Fletcher RH, et al. (2005) Socioeconomic and racial patterns of colorectal cancer screening among Medicare enrollees in 2000 to 2005. Cancer Epidemiol Biomarkers Prev 18: 2170-2175.

50. Katz ML, Tatum C, Dickinson SL (2007) Improving colorectal cancer screening by using community volunteers: results of the Carolinas cancer education and screening (CARES) project. Cancer 110: 1602-1610.

51. Goel MS, Wee CC, McCarthy EP, Davis RB, Ngo-Metzger Q, et al. (2003) Racial and ethnic disparities in cancer screening: the importance of foreign birth as a barrier to care. J Gen Intern Med 18: 1028-1035.

52. Coughlin SS, Thompson TD, Seeff L, Richards T, Stallings F,et al. (2002) Breast, cervical, and colorectal carcinoma screening in a demographically defined region of the southern U.S. Cancer 95: 2211-2222.

53. Oluyemi AO (2014) Colorectal Cancer Screening in High Risk Groups Is Increasing, Although Current Smokers Fall Behind. Cancer 120: 2106-2113.

54. Dolan NC, Ferreira MR, Fitzgibbon ML (2005) Colorectal cancer screening among African-American and white male veterans. Am J Prev Med 28: 479482

55. O'Malley AS, Forrest CB, Mandelblatt J (2002) Adherence of low-income women to cancer screening recommendations. J Gen Intern Med 17: 144-154.

56. Shah M, Zhu K, Potter J (2006) Hispanic acculturation and utilization of colorectal cancer screening in the United States. Cancer Detect Prev 30: 306312 